\title{
Minimizing aerosol bone dust during autopsies
}

\author{
Jip M. E. Pluim ${ }^{1,2} \cdot$ Arjo J. Loeve ${ }^{2,3} \cdot$ Reza R. R. Gerretsen ${ }^{1}$
}

Accepted: 3 July 2019 / Published online: 24 July 2019

(C) Springer Science+Business Media, LLC, part of Springer Nature 2019

\begin{abstract}
When sawing bone for medical or medico-legal procedures, fine, airborne dust is produced (aerosols) that can pose a health hazard when inhaled. The aim of this study was to determine the influence of saw blade frequency and contact load, bone condition, test environment, and saw blade type, on the production of aerosol particles. A custom test setup was designed, manufactured and used in 8 bone sawing experiments, using a particle counter to determine the production of aerosol particles while varying the 5 chosen parameters. The number of counted particles was highest with higher saw blade frequencies, lower saw blade contact loads, in dry completely skeletonized bone compared to fresh bone, and using an electrical oscillating saw compared to hand-sawing. Under all conditions, the high amount of aerosol counted posed potential health risks. The ventilation system that we tested was adequate in removing the produced particles, but these high-tech systems are not always available in developing countries or emergency situations. The production of aerosols can be reduced by optimizing the sawing parameters. However, even the lowest number of aerosol particles counted during the current study was high enough to cause potential health risks to practitioners. Safety precautions should be taken, such as external ventilation, proper breathing gear, and adequate protocols, to truly minimize the risk in all bone sawing scenarios.
\end{abstract}

Keywords Aerosol $\cdot$ Bone dust $\cdot$ Sawing parameters $\cdot$ Autopsy $\cdot$ Pathology $\cdot$ Biosafety

\section{Introduction}

When operating on the human body (electro-) mechanical tools are often used. Although cutting incidents with sharps or needles are well known health hazards, inhalation of surgical smoke or aerosols (solid or liquid airborne particles) produced by tools is often overlooked and can lead to, for

Jip M. E. Pluim

jippluim@gmail.com

Arjo J. Loeve

a.j.loeve@ tudelft.nl

Reza R. R. Gerretsen

r.gerretsen@nfi.minvenj.nl

1 Department of Forensic Anthropology, Netherlands Forensic Institute, Laan van Ypenburg 6, 2497GB The Hague, Netherlands

2 Department of BioMechanical Engineering, Faculty of Mechanical, Maritime and Materials Engineering, Delft University of Technology, F-0-200, Mekelweg 2, 2628CD Delft, The Netherlands

3 Co van Ledden-Hulsebosch Centrum, Science Park Building 904, 1098XH Amsterdam, The Netherlands example, respiratory irritations, transmission of infections, and genotoxicity [1]. Safety awareness for high risk airborne transmissible pathogens such as tuberculosis (TB) [2] or Severe Acute Respiratory Syndrome (SARS) does exist [3], however, the health risks associated with the aerosolization of pathogens in the skin, blood or other bodily material remain uncertain. These aerosolized pathogens could include Hepatitis B and C, Streptococci, and Human Immunodeficiency Virus (HIV), of which airborne transmissions are rare but have been reported or proven plausible during surgery or autopsy sessions [4]. Additionally, non-pathogen-carrying aerosols can pose health hazards when inhaled and deposited in the airways, as with industry smog, car exhaust gas, cigarette smoke or urban pollution [5].

This study focuses on aerosols produced when sawing bone during forensic autopsies. These aerosols spread widely throughout the surroundings of the operation site, possibly reaching the respiratory tract of the operator [6-10]. Particles smaller than $10 \mu \mathrm{m}$ are within the respirable range and can remain suspended in the air for hours after sawing [11].

The goal of this study was to investigate the effects of several sawing parameters that are relevant in daily practice during forensic autopsies on the production of aerosols, in 
order to inherently minimize the health risk faced by forensic practitioners.

\section{Materials and methods}

A prior pilot study was performed on the influence of saw blade frequency and saw blade contact load on the production of aerosol in dry bone [12]. For the current study three additional parameters were selected that closely represent the variety in sawing parameters faced in daily practice. In eight experiments the influences of saw blade frequency and saw blade contact load were studied against the influences of three selected parameters: bone condition, test environment, and saw blade type. An overview of all experiments is given in Table 1 .

A setup (Fig. 1) was designed and manufactured so that a saw blade could consistently and accurately be lowered on a fixed bone specimen using a vertical sliding platform. Dumbbell weights were used to set the saw blade contact load $(3,4$, and $5 \mathrm{~kg})$, a custom-built tachometer was used to set and read the saw blade frequency $(150,200$, and $250 \mathrm{~Hz}$ for the oscillating saw, and 15 and $25 \mathrm{~Hz}$ for hand sawing).

Three different bone conditions were used: dried archeological human femora (cat. D.4 [13]), greasy archeological human femora (cat. D.3 [13]), and fresh porcine metacarpal and metatarsal specimens (cat. A.1 [13]).

Tests were conducted in three environmental conditions: inside a closed acrylic glass box, in an open examining room with uncontrolled ventilation, and on a custom designed autopsy table with a built-in ventilation system with a ventilation capacity of $3000 \mathrm{~m}^{3} / \mathrm{h}$.

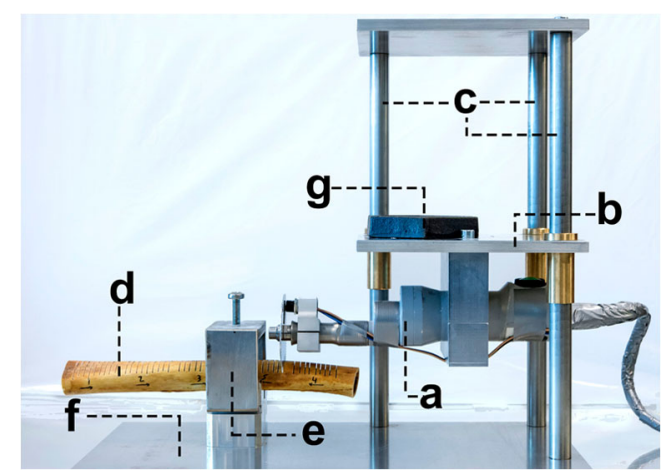

Fig. 1 Experimental setup used to cut bone samples, consisting of: an oscillating saw (a) fastened to a vertical sliding platform (b) guided by 3 stainless steel rods and brass sliding bearings (c). The bone specimen (d) was clamped in a v-groove holder (e), that was connected to an aluminum base plate (f). Interchangeable weights could be attached to the platform (g)

Three saw blade types were used: an electrical oscillating saw (DeSoutter NS3, DeSoutter Medical Limited, UK), a rough toothed 9 teeth per inch Satterlee type handsaw (FH325R, Aesculap AG, Germany), and a fine toothed 18 teeth per inch metal-blade handsaw (Phantom, Van Ommen B.V., The Netherlands).

A Fluke 985 particle counter (Fluke corporation, Everett, Washington, USA) counted the number of aerosol particles of sizes $0.3,0.5,1.0,2.0,5.0$, and $10 \mu \mathrm{m}$.

A two-way ANOVA was used to test for the effect of saw blade frequency and contact load on the number of individual particles (sized $0.3,0.5,1.0,2.0,5.0$, and $10 \mu \mathrm{m}$ ), the total number and total surface area of the counted aerosol particles. A three-way ANOVA was used to investigate the effect of saw blade frequency and contact load between the eight experiments, and thus the effects of the bone condition, test

Table 1 Overview of the variables tested in the eight experiments that were performed

Tested variables and experiment numbers

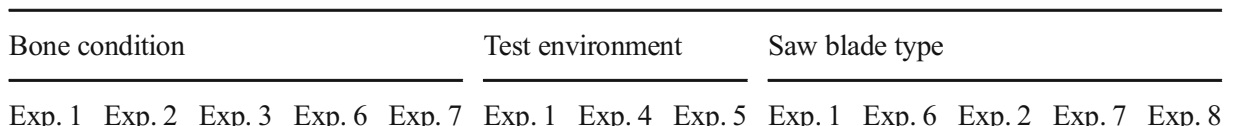

Exp. 1 Exp. 2 Exp. 3 Exp. 6 Exp. 7 Exp. 1 Exp. 4 Exp. 5 Exp. 1 Exp. 6 Exp. 2 Exp. 7 Exp. 8

\begin{tabular}{|c|c|c|c|c|c|c|c|c|c|c|c|c|c|c|}
\hline \multirow[t]{3}{*}{ Bone condition } & Dry bone cat. D.4[13] & D & & & D & & $\mathrm{D}$ & $\mathrm{D}$ & $\mathrm{D}$ & $\mathrm{D}$ & $\mathrm{D}$ & & & \\
\hline & Greasy bone cat. D.3[13] & & G & & & G & & & & & & G & G & G \\
\hline & Fresh bone cat. A.1[13] & & & $\mathbf{F}$ & & & & & & & & & & \\
\hline \multirow{3}{*}{$\begin{array}{l}\text { Test } \\
\text { environment }\end{array}$} & Closed environment & $\mathrm{C}$ & $\mathrm{C}$ & $\mathrm{C}$ & $\mathrm{C}$ & $\mathrm{C}$ & $\mathbf{C}$ & & & $\mathrm{C}$ & $\mathrm{C}$ & $\mathrm{C}$ & $\mathrm{C}$ & $\mathrm{C}$ \\
\hline & Open environment & & & & & & & $\mathbf{O}$ & & & & & & \\
\hline & Active ventilation & & & & & & & & $\mathbf{A}$ & & & & & \\
\hline \multirow[t]{3}{*}{ Saw blade type } & Electric oscillating saw & $\mathrm{E}$ & E & $\mathrm{E}$ & & & E & E & $\mathrm{E}$ & $\mathbf{E}$ & & $\mathbf{E}$ & & \\
\hline & Satterlee bone-saw & & & & $\mathrm{B}$ & $\mathrm{B}$ & & & & & B & & B & \\
\hline & Metal-saw & & & & & & & & & & & & & $\mathbf{M}$ \\
\hline
\end{tabular}

The grouped columns show which experiments are compared to find the influence of bone condition, test environment, and saw blade type, with the independent variable shown in bold 
environment, or saw blade type. Effects were considered significant when $p \leq 0.05$. A more detailed description of the methodology can be found in our previously published research [14].

\section{Results}

The number of counted particles was highest with higher saw blade frequencies, lower saw blade contact loads, in dry completely skeletonized bone compared to fresh bone, and using an electrical oscillating saw compared to hand-sawing. The tested ventilation system was adequate in removing the produced particles.

A significant effect of saw blade frequency and contact load on the number of aerosol particles was found only when sawing in dry, greasy, and fresh bone, in a closed environment, using an electrical oscillating saw: a lower saw blade frequency or higher saw blade contact load result in less counted particles.

The highest number of particles was produced when sawing in dry bone, the lowest in fresh bone, showing a significant effect of bone condition. A significant effect of the test environment was found: more particles were counted in the closed environment than in the open environment, or with active ventilation. The effect of the saw blade type proved statistically significant; the number of particles was higher with the Satterlee bone-saw than with the metal-saw.

Typical examples of single measurements are shown in Fig. 2 for experiment 2 and in Fig. 3 for experiment 5. The complete and detailed dataset is recorded in [14].

\section{Discussion}

No effect of saw blade frequency or contact load was found in the open environment or under active ventilation, suggesting that influences of the environment dominate the number of inhaled aerosol particles.

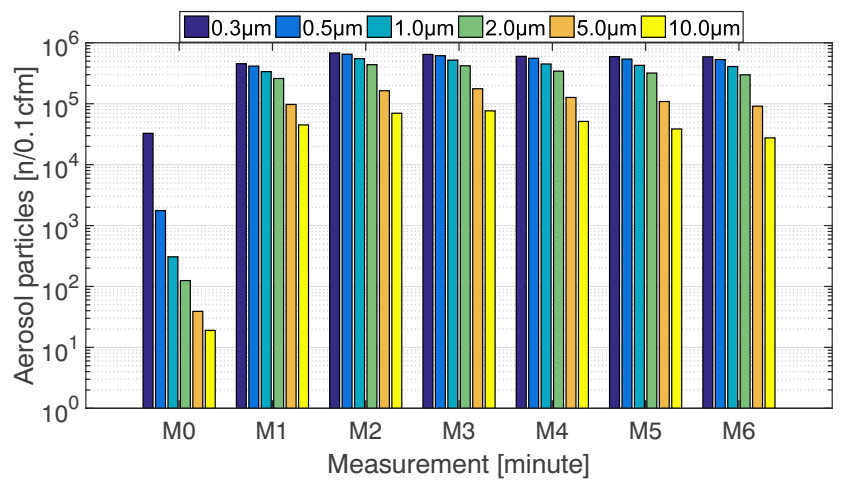

Fig. 2 Typical results over 6 min of particle counting in experiment 2. Note that the vertical axis is logarithmic

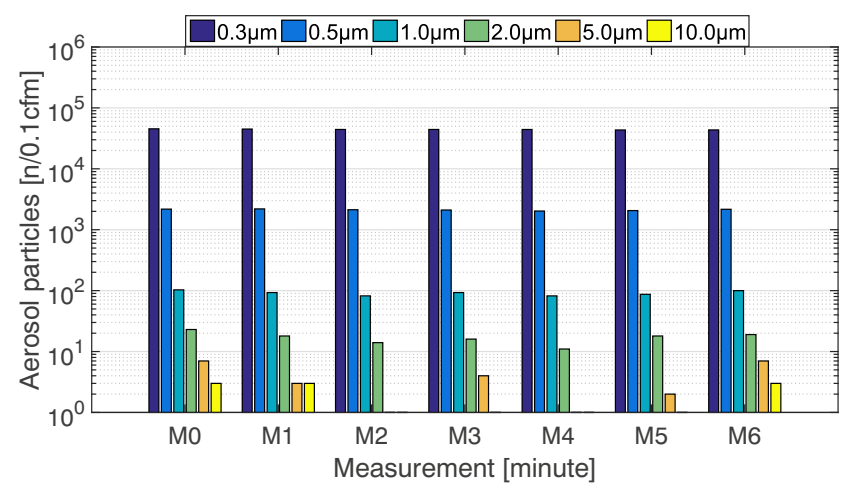

Fig. 3 Typical results over 6 min of particle counting in experiment 5 . Note that the vertical axis is logarithmic

In fresh bone, smaller sized particles occurred more than larger sized particles, suggesting that the organic materials and water present in fresh bone might themselves have been aerosolized by sawing. These organic materials are most hazardous, as bone marrow and blood may contain potentially hazardous pathogens.

The number of particles counted at the ventilated autopsy table were within the normal numbers of particles generally found in air and were not necessarily aerosol produced by sawing. However, the number of particles counted over the autopsy table with active ventilation, even though extremely low, was still well over the limit advised for surgeries [15], and validated safety protocols and precautions should be taken $[16,17]$.

Saw blade kerf mark analysis in forensic science is mainly focused on trace analysis, but could be used to lower the production of aerosols. It should be noted, however, that increasing protection against aerosols is most likely much more effective than reducing aerosols by optimizing the saw blade, as the effect of the saw blade, although significant, but still small. Furthermore, even in the best situation the number of particles was still above the limit advised for surgeries.

\section{Conclusion}

The production of aerosol dust particles by sawing in bone can pose health risks for those near the site of operation, even for long periods of time after the procedure has finished. The fine particles are within the respirable range and can cause harm to the respiratory tract, or potentially transfer harmful pathogens. It was found that active ventilation within the tested autopsy table can remove nearly all of these aerosol dust particles from the air. A proper choice of sawing parameters could minimize the production of aerosols: sawing by hand using a sharp, fine toothed hacksaw was found to be the best option. When an electric oscillating saw is used, decreasing the saw blade frequency or increasing the saw blade contact load can be used to minimize aerosol production. However, even for the 
parameters with the lowest production this intrinsic decrease in particles is slight, and the number of aerosol bone particles that are produced still pose a serious health hazard to anyone near the sawing site. Adequate protective breathing gear, ventilation systems and safety protocols should be used to minimize the risks faced by practitioners.

\section{Key points}

1. Aerosol bone dust particles, that have the potential to be carrying pathogens, are produced by sawing during autopsies and can cause health risks when inhaled.

2. The influences of saw blade frequency, saw blade contact load, saw type, bone type and sawing environment on the production of aerosol bone dust particles was tested in 8 experiments.

3. A lower number of particles was counted with lower saw blade frequencies, higher saw blade load, in fresher bone, and using a hand-saw instead of an electrical saw, but was still high enough to be hazardous.

4. Active ventilation can remove nearly all produced bone aerosols, but might not be generally available and should be tested under more stressing circumstances.

5. Sawing in bone should only be done when adequate protective breathing equipment, ventilation systems, and safety protocols are used to minimize the risks faced by practitioners.

Acknowledgements The authors would like to thank Hannes Habraken for building the experimental setup, Maud van Velthoven for the photographs in this paper, Lucas Jimenez-Bou for contributing to the experimental design, and the autopsy assistants of the Netherlands Forensic Institute for their support during the measurements in the autopsy room.

Author's contributions Jip M.E. Pluim: Primary researcher, article preparation. Corresponding author.

Arjo J. Loeve: Study design, article proofing.

Reza R.R. Gerretsen: Study design, article proofing.

\section{Compliance with ethical standards}

Conflict of interest The authors declare that they have no conflict of interest.

Ethical approval For this type of study formal consent is not required.

Informed consent Not required.

\section{References}

1. Barrett WL, Garber SM. Surgical smoke - a review of the literature. Is this just a lot of hot air? Surg Endosc. 2003;17: 979-87.

2. Templeton GL, Illing LA, Young L, Cave MD, Stead WW, Bates JH. The risk for transmission of mycobacterium tuberculosis at the bedside and during autopsy. Ann Intern Med. 1995;122:922-5.

3. Tang JW, Li Y, Eames I, Chan PKS, Ridgway GL. Factors involved in the aerosol transmission of infection and control of ventilation in healthcare premises. J Hosp Infect. 2006;64: 100-14.

4. Burton JL. Health and safety at necropsy. J Clin Pathol. 2003;56: 254-60.

5. Schulz H, Harder V, Ibald-Mulli A, Khandoga A, Koenig W, Krombach F, et al. Cardiovascular effects of fine and ultrafine particles. J Aerosol Med. 2005;18:1-22.

6. Kernbach-Wighton G, Kuhlencord A, Rossbach K, Fischer G. Bone-dust in autopsies: reduction of spreading. Forensic Sci Int. 1996;83:95-103.

7. Kernbach-Wighton G, Kuhlencord A, Saternus KS. Knochenstäube bei der autopsie. Entstehung, ausbreitung, kontamination. Pathologe. 1998;19:355-60.

8. Wenner L, Pauli U, Summermatter K, Gantenbein H, Vidondo B, Posthaus $\mathrm{H}$. Aerosol generation during bone-sawing procedures in veterinary autopsies. Vet Pathol. 2017;54:425-36.

9. Green FHY, Yoshida K. Characteristics of aerosols generated during autopsy procedures and their potential role as carriers of infectious agents. J Occup Environ Hyg. 1990;5:853-8.

10. Saternus KS, Kernbach-Wighton G. On the contamination of ambient air by preparations carried out with a band-saw. Forensic Sci Int. 1999;104:163-71.

11. Harper GJ. Airborne micro-organisms: survival tests with four viruses. J Hyg. 1961;59:479-86.

12. Pluim JME, Jimenez-Bou L, Gerretsen RRR, Loeve AJ. Aerosol production during autopsies: the risk of sawing in bone. Forensic Sci Int. 2018;289:260-7.

13. Galloway A. The process of decomposition: a model from the Arizona-Sonoran desert. In: Haglund WD, Sorg MH, editors. Forensic taphonomy: the postmortem fate of human remains. Boca Raton: CRC Press; 1997. p. 139-50.

14. Pluim JME. Aerosol production during autopsies: Minimising health risks of bone sawing. Masters Thesis, Delft University of Technology. 2019. http://resolver.tudelft.nl/uuid:1837c83b-bbd142a3-98e9-8340942b3dc9.

15. Dharan S, Pittet D. Environmental controls in operating theatres. J Hosp Infect. 2002;51:79-84.

16. Weber A, Willeke K, Marchloni R, Myojo T, McKay R, Donnelly $\mathrm{J}$, et al. Aerosol penetration and leakage characteristics of masks used in the health care industry. Am J Infect Control. 1993;21:167-73.

17. Chen SK, Vesley D, Brosseau LM, Vincent JH. Evaluation of single-use masks and respirators for protection of health care workers against mycobacterial aerosols. Am J Infect Control. 1994;22:65-74.

Publisher's note Springer Nature remains neutral with regard to jurisdictional claims in published maps and institutional affiliations. 